\title{
Modification of the cardiometabolic risk and quality of life through an exercise program on Mexican breast cancer survivors
}

\author{
ANDREA PEGUEROS-PÉREZ $\longleftarrow$, REBECA SALAS-ROMERO, ARIADNA DEL VILLAR-MORALES, JOSÉ \\ G. FRANCO-SÁNCHEZ
}

National Center for Research and Care in Sports Medicine, National Institute of Rehabilitation "Luis Guillermo Ibarra", Mexico City, Mexico

\begin{abstract}
Background: Survival to breast cancer has increased all over the world; however, secondary and long-term side effects which may increase cardiometabolic risk (CMR) and deteriorate the quality of life of survivors may occur to oncological treatments. The objective of this work was to evaluate the modification of these factors after a combined and progressive exercise program. Methods: Self-controlled clinical study. Women younger than 65 years old, survivors of breast cancer, and with authorization from their oncologist signed an informed consent and followed a combined and progressive exercise program of 24 weeks. The CMR was evaluated with biochemical, anthropometric and cardiorespiratory fitness (CRF) parameters; the quality of life was evaluated (questionnaires SF-36 and FACT-B) at the beginning and end of the program. Descriptive statistics and evidence of Wilcoxon sign test were used ( $p<.05$, SPSS v20.0 Windows). Results: Thirty women, 52 year-olds with a body mass index (BMI) of $28.9 \mathrm{~kg} / \mathrm{m}^{2}$ were evaluated. After 24 weeks there was a significant improvement for the CRF with an increase of $2.9 \mathrm{METs}$ and $10.1 \mathrm{~mL}^{*} \mathrm{~kg}^{-1 *} \mathrm{~min}^{-1}$, and for the quality of life with an increase of 9.0 and 11.1 points (SF-36 and FACT- B respectively). The BMI decreased $1.1 \mathrm{~kg} / \mathrm{m}^{2}$, the waist $3.7 \mathrm{~cm}$, the fat mass $3.0 \%$ and the muscle mass increased $2.9 \%$. Conclusions: The exercise program decreased the CMR by increasing CRF, improving body composition and decreasing abdominal fat mass; these results lead to the perception of a better quality of life.
\end{abstract}

Keywords: Breast cancer; Survivors; Exercise; Cardiometabolic risk factors; Quality of life.

Cite this article as:

Pegueros-Pérez, A., Salas-Romero, R., del Villar-Morales, A., \& Franco-Sánchez, J.G. (2020). Modification of the cardiometabolic risk and quality of life through an exercise program on Mexican breast cancer survivors. Journal of Human Sport and Exercise, 15(2), 442-456. doi:https://doi.org/10.14198/jhse.2020.152.18

Corresponding author. National Center for Research and Care in Sports Medicine (NCRCSM), National Institute of Rehabilitation "Luis Guillermo Ibarra Ibarra". 289 Mexico-Xochimilco Avenue, Zip Code 14389, Mexico City, Mexico. https://orcid.org/0000-0001-6269-2282

E-mail: apegueros@gmail.com

Submitted for publication May 2019

Accepted for publication July 2019

Published June 2020 (in press July 2019)

JOURNAL OF HUMAN SPORT \& EXERCISE ISSN 1988-5202

(C) Faculty of Education. University of Alicante

doi:10.14198/jhse.2020.152.18

$442|2020|$ ISSUE 2 | VOLUME 15

C 2020 University of Alicante 


\section{INTRODUCTION}

Breast cancer is the second most common type of cancer in the world and the most frequent in women (Bray et al., 2018). In Mexico, it ranks first in incidences of malignant neoplasms and is the leading cause of cancer death in women over 25 years of age (Información estadística cáncer de mama, 2016).

Despite the high mortality rates, the percentage of women who survive this type of cancer is increasing as a result of opportune diagnosis and the efficacy of oncological treatments; therefore the health system faces the challenge of decreasing the rates of the disease recurrence or premature death, and improving the quality of survival of these patients.

Five-year survival rates range from $80 \%$ or more in North America, Sweden and Japan, to $60 \%$ in middleincome countries or less than 40\% in low-income countries (Allemani et al., 2015).

The survival rates reported in Mexico have been $83.1 \%$ for 5 -year global survival, and $81.8 \%$ for 5 -year disease-free survival (Maffuz-Aziz et al., 2016). The percentage of overall survival is higher in the early stages: $96.8 \%$ for stages I and IIA, $74.6 \%$ for locally advanced stages (IIB, IIIA, IIIB and IIIC).

Women who survive may have late and long-term side effects as a result of cancer treatments, like lymphedema, cardiovascular problems (arrhythmias, congestive heart failure, hypertension), hormonal or osteoarticular problems, peripheral neuropathy, and emotional disorders (Bodai \& Tuso, 2015).

These events affect the patients' quality of life in practically all its domains and can lead to a decrease in cardiorespiratory fitness; in fact, it is considered that almost a third of women surviving breast cancer have a peak oxygen consumption lower than the limit required for an independent life (Haykowsky et al., 2017).

A sedentary lifestyle predominates in this population; it has been reported that only $20-30 \%$ of the patients are active after the treatments (Garcia \& Thomson, 2014). This may promote the development of overweight, obesity, dyslipidaemias, insulin resistance, glucose intolerance, diabetes mellitus type 2 , and cardiovascular disease, all which increase cardiometabolic risk.

The regular practice of exercise is an effective intervention to improve cardiorespiratory fitness, some biomarkers of cardiometabolic risk, and the quality of life of these patients. However, its effect may vary depending on age, health status, and the exercise program prescribed (Lin et al., 2015; Mishra et al., 2012; Zeng et al., 2014).

It is necessary to offer alternatives that allow surviving women to incorporate exercise into their lifestyle. Therefore, the objective of this study was to evaluate the effect of a combined, individualized, and progressive physical exercise program of 24 weeks on cardiometabolic risk factors and quality of life of survivors of breast cancer. To our best knowledge, this is the first study conducted in Mexican women, and it could become the basis for a model of care addressed to these patients.

\section{MATERIALS AND METHODS}

The objectives and interventions during the study were explained to the patients who gave their approval by signing the informed consent in compliance with the Helsinki declaration. The study was approved by the 
Local Research and Ethics Committee of the National Institute of Rehabilitation "Luis Guillermo Ibarra" (NIRLGII), with registration number 29/14.

The study included women under 65 years of age who were breast cancer survivors, sedentary, without any data of osteoporosis, with mobility arches of $\geq 90^{\circ}$ in the upper limbs, without edema, who had concluded their oncological treatments at least 3 months before and had the authorization from their treating medical oncologists.

Patients who did not comply with $80 \%$ attendance to the exercise sessions or who presented a lesion that took more than 15 days to heal were eliminated from the study. Patients with signs and symptoms of depression and/or severe anxiety, had a body mass index $>40 \mathrm{~kg} / \mathrm{m}^{2}$, any metabolic disorder without control (diabetes mellitus type 2, hyper or hypothyroidism), severe hypertension induced by the exercise or presented contraindications to the practice of exercise according to the criteria of the American College of Sports Medicine (ACSM) were excluded (American College of Sports Medicine, 2017). The pre-participation risk was stratified according to the ACSM.

\section{Study design}

The study was a self-controlled clinical trial carried out at the National Center for Research and Care in Sports Medicine of the NIRLGII of the Secretary of Health. The study was conducted with a convenience sample of 30 patients who met the inclusion criteria. The intervention lasted 24 weeks during which patients followed an individualized, combined, dosed, and supervised program of physical exercise with periodic progression; they also followed nutritional recommendations in order to improve their eating habits.

The cardiometabolic risk was evaluated with the body mass index (BMI), waist circumference, biochemical variables (LDL, HDL, triglycerides, cholesterol, glucose, and insulin resistance index HOMA), systemic blood pressure, and cardiorespiratory fitness. The latter was assessed by maximal oxygen consumption $\left(\mathrm{VO}_{2 \max }\right)$ and metabolic equivalents (METs). Quality of life was evaluated with the SF-36 health, and the Functional Assessment of Cancer Therapy (FACT-B for patients with breast cancer) Spanish version questionnaires. The evaluations were made before starting the intervention and 24 weeks later; the cardiorespiratory capacity for the progression of aerobic exercise was re-evaluated during week 13.

\section{Anthropometry}

Body weight and height were measured in a stadiometer and electronic scale (SECA, model 703, Germany) with patients wearing light clothing. The waist circumference was measured at the level of the umbilical scar. The body density was determined by the Durnin-Womersely equation, while the percentage of fat mass was obtained with the Siri formula; the percentage of muscle mass was calculated by Matiegka's four-component method (Heyward \& Wagner, 2004).

Additionally, the circumference of 5 regions of both arms was measured before and after each exercise session as a preventive control for the development of lymphedema. The regions measured were metacarpophalangeal, biestiloid, supracondylar, forearm, and relaxed arm joints. All measurements were made following the international standards for anthropometric assessment and were carried out by certified personnel.

\section{Laboratory tests}

Patients were instructed to avoid alcohol consumption and not to exercise 24 hours before taking blood samples; and they attended lab under an 8-hour fast. Samples were taken for the determination of glucose 
levels (mg/dL), insulin $(\mu \mathrm{U} / \mathrm{mL})$, total cholesterol $(\mathrm{mg} / \mathrm{dL})$, high and low density lipoproteins (HDL, $L D L)$ $(\mathrm{mg} / \mathrm{dL})$, triglycerides $(\mathrm{mg} / \mathrm{dL})$, liver enzymes alanine aminotransferase (ALT) and aspartate aminotransferase (AST) (IU/L), uric acid (mg/dL), total proteins $(\mathrm{g} / \mathrm{dL})$, total bilirubin $(\mathrm{mg} / \mathrm{dL})$, phosphatase alkaline (U/L), gamma glutamyl transferase (U/L) and blood biometry. The HOMA-IR index ([glucose mg/dL $\mathrm{x}$ insulin $\mu \mathrm{U} / \mathrm{mL}$ ] $/ 405$ ) was determined, considering a value $>2.4$ as insulin resistance for the Mexican population. The samples were processed in the NIRLGII central laboratory.

\section{Cardiorespiratory capacity}

The cardiorespiratory capacity was assessed by means of a maximal effort test on a treadmill according to the Balke protocol (Heyward, 2008). The stress test was performed after cardiac evaluation with an electrocardiogram at rest with 12 leads. Based on the results obtained, the maximum oxygen consumption $\left(\mathrm{VO}_{2 \max } \mathrm{mL}^{*} \mathrm{~kg}^{-1 *} \mathrm{~min}^{-1}\right)$ and the metabolic equivalents (METs) were calculated.

\section{Quality of life}

The quality of life was assessed through the application of the SF-36 health questionnaire and the FACT-B (Spanish version) both validated for Mexican population (Fernández-Suárez, Blum-Grynberg, AguilarVillalobos, Bautista-Rodríguez, 2010; Zúniga, Carrillo-Jiménez, Fos, Gandek, Medina-Moreno, 1999). Questionnaire SF-36 provides a profile on the state of health through 8 dimensions (physical function, physical role, body pain, general health, vitality, social function, emotional role, and mental health); it encompasses the results in physical and mental health. The FACT-B values the quality of life in a multidimensional way considering the physical, functional, emotional, and socio-familiar well-being, and it includes a specific sub-scale for patients with breast cancer. The Trial Outcome Index (TOI) was calculated by adding the physical and functional well-being and the sub-scale for breast cancer, a measure that focuses on the impact of medical treatment. For both questionnaires and TOI, the higher the score, the better the quality of life. The questionnaires were applied before starting the intervention and at the end of it.

\section{Exercise program}

The exercise program lasted 24 weeks, it was individualized according to the capabilities of each patient, supervised by trained sports trainers and with periodic progression. The program was designed to perform the strength and the aerobic component on alternate days; it consisted of one macrocycle of 24 weeks, two mesocycles of 12 weeks each, 6 microcycles of 3 to 6 weeks, 22 cycles of 1 week, and 91 sessions (Table 1).

The patients performed the program in groups of 3-5 or individually; their attendance to the exercise sessions was recorded in a list.

Each session began with 5 minutes of joint movement in cephalo-caudal direction and 10 minutes of cycling or treadmill warm-up; and they finished with general flexo-elasticity movements for 10 minutes as recovery. The patients used a compression sleeve on the affected arm during all the exercise sessions.

\section{Strength training}

The strength training included isotonic exercises of the different muscle groups, which started at the centre of the body in order to achieve adequate stability and followed with the upper limbs and lower limbs.

The first two weeks focused on promoting adaptation to exercise and to supervise that the execution technique was appropriate taking into account that the patients were sedentary. For the exercises focused 
on the centre of the body, the Swiss ball was used; the frequency was 2 days/week at very light intensity $(<$ $30 \%$ 1RM) (American College of Sports Medicine, 2017).

Table 1. Description of the combined exercise program.

\section{Baseline evaluation Week 0}

Weeks 1-2. Anatomical adaptation phase

Frequency: 2 days/week

Intensity: < 30\% 1RM

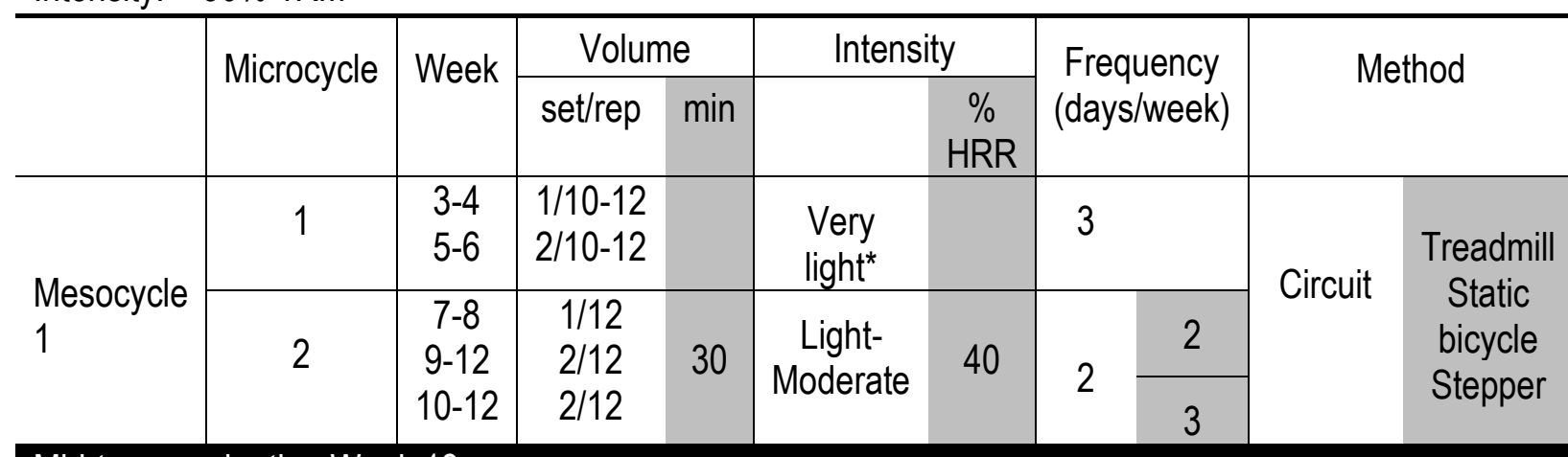

\section{Mid-term evaluation Week 13}

\begin{tabular}{|c|c|c|c|c|c|c|c|c|c|c|}
\hline \multirow{4}{*}{$\begin{array}{l}\text { Mesocycle } \\
2\end{array}$} & 3 & $\begin{array}{l}14 \\
15 \\
16\end{array}$ & $\begin{array}{c}2 / 8 \\
2 / 12 \\
3 / 12\end{array}$ & 40 & Light & \multirow{3}{*}{$\begin{array}{l}40- \\
60\end{array}$} & \multirow{3}{*}{4} & \multirow{3}{*}{3} & \multirow{4}{*}{ Stations } & \multirow{4}{*}{$\begin{array}{c}\text { Treadmil } \\
\text { Static } \\
\text { bicycle } \\
\text { Stepper }\end{array}$} \\
\hline & 4 & $\begin{array}{l}17 \\
18 \\
19\end{array}$ & $\begin{array}{c}2 / 8 \\
2 / 12 \\
3 / 12\end{array}$ & 50 & Moderate & & & & & \\
\hline & 5 & $\begin{array}{l}20 \\
21 \\
22\end{array}$ & $\begin{array}{c}2 / 8 \\
2 / 12 \\
3 / 12\end{array}$ & 60 & Moderate & & & & & \\
\hline & 6 & $\begin{array}{l}23 \\
24 \\
24\end{array}$ & $\begin{array}{l}/ 1 / 8 \\
2 / 12\end{array}$ & $\begin{array}{l}30 \\
20\end{array}$ & Light & 40 & 2 & 2 & & \\
\hline
\end{tabular}

\section{Final evaluation Week 25}

Note. The white columns of volume, intensity, frequency and method correspond to the characteristics of the strength training, while the shaded ones correspond to the aerobic training. 1 RM: One repetition maximum; Rep: Repetitions; HRR: Heart rate reserve.

In weeks 3 to 6 , the number of exercises was increased to 10 and the use of dumbbells and elastic bands was added. The intensity was light ( $40 \%$ of the 1 RM), with circuit method; the volume was 1 set of 10 to 12 repetitions and progressed in week 5 to two sets, the rest period was 2 minutes between sets, the speed of execution was moderate, and the frequency was 3 days/week (Kraemer et al., 2002).

As of week 7, the training means were changed to weight machines, and the circuit method continued with work of both upper and lower train in the same session. The progression in these weeks was based on volume, thus the number of repetitions and sets was increased.

In week 14 the method was modified to stations; the frequency was 2 days for upper train and 2 days for lower train in order to maximize the specific force gain. The rest periods were from 2 to 3 minutes between 
series, the speed of execution was slow to moderate and the intensity was light but progressed to moderate with increments of 10\% each week (40\% to $60 \%$ of the 1RM) (American College of Sports Medicine, 2017).

In order to achieve greater attachment to the program, it included variation of the exercises as well as a gradual progression. The volume was increased each week and the intensity was increased by $10 \%$ every 3 weeks, according to the recommendation of the ACSM strength training progression models (Kraemer et al., 2002). Table 2 shows the exercises performed and the equipment used in each stage of the training.

Table 2. Equipment used and exercise performed in each stage of the strength training.

\begin{tabular}{|c|c|c|}
\hline & Equipment & Exercise \\
\hline Weeks 1-2 & Elastic bands, dumbbells, Swiss ball & $\begin{array}{l}\text { Reverse roll-up, lumbar extension*, dumbbell } \\
\text { squats }^{*} \text {, crunch*', dumbbell biceps curl }{ }^{*} \text {. }\end{array}$ \\
\hline \multicolumn{3}{|l|}{ Microcycle } \\
\hline 1 & Elastic bands, dumbbells, Swiss ball & $\begin{array}{l}\text { Exercises of the previous weeks }+ \text { triceps with } \\
\text { dumbbells*, chest press with elastic bands*, } \\
\text { seated row with elastic bands*, obliques abs }{ }^{*} \text {, } \\
\text { dumbbells lateral raise }{ }^{*} \text {. }\end{array}$ \\
\hline 2 & $\begin{array}{l}\text { Weight machines, Swiss ball, } \\
\text { dumbbells }\end{array}$ & $\begin{array}{l}\text { Knee extension, biceps curl, leg curl, dumbbells } \\
\text { lateral raise, leg press, dumbbell chest press, leg } \\
\text { press calf raise, lumbar extension*, dumbbell } \\
\text { squats }{ }^{*} \text {, triceps extension, crunches. }\end{array}$ \\
\hline \multirow{2}{*}{$3-6$} & \multirow{2}{*}{ Same as microcycle 2} & $\begin{array}{l}\text { Knee extension, leg curl, leg press, dumbbell } \\
\text { squats*, leg press calf raise. }\end{array}$ \\
\hline & & $\begin{array}{l}\text { Biceps curl, lateral raise, triceps extension, front } \\
\text { raise, chest press. }\end{array}$ \\
\hline
\end{tabular}

${ }^{*}$ For these exercises the Swiss ball is used as support.

\section{Aerobic exercise training}

The aerobic exercise started from week 7 in a continuous mode, its alternated activities with walking, static bicycle, and stepper in order to improve adherence to the training program. The patients trained at $40-60 \%$ of the heart rate reserve obtained in the baseline assessment; it was monitored during each session by using heart rate monitors (Polar Electro, model T31C, Finland) in order to ensure that the training load was the appropriate. The program was re-adjusted in week 13 according to the results of the mid-term evaluation.

All the components of exercise prescription decreased in the two weeks prior to the final evaluation in order to achieve better performance.

The frequency, intensity and volume of strength and aerobic training is detailed in Table 1.

The patients received nutritional recommendations after an interview with the specialist in order to determine the eating habits and calculate the daily caloric intake. 


\section{Statistical analysis of results}

The SPSS v.20 program for Windows (Chicago, IL, USA) was used for all analyses. The data are shown as percentages, averages and medians (minimum-maximum). Normality was assessed with the Shapiro-Wilkins test. The significance of the changes in the study variables between the start and end of the intervention was determined by the Wilcoxon sign test, considering a value $p<.05$ as significant in all cases.

\section{RESULTS}

The sample was formed with 30 patients, from which 24 completed the exercise program thoroughly (91 sessions, 24 weeks). Six patients were eliminated due to loss of follow-up (5 patients due to lack of adherence and 1 patient due to breast reconstruction surgery); on average, the six patients attended 52 sessions (15.5 weeks). In case of absence, the people responsible of the study contacted them on the telephone; patients were allowed to replenish the session(s) when they did not exceed 3 consecutive ones. In these cases, patients always returned to the session number where they interrupted the program. No adverse events related to the intervention were observed.

Table 3 shows the demographic data of the patients. The BMl $\left(28.9 \mathrm{~kg} / \mathrm{m}^{2}\right)$ placed the patients in the overweight range according to the classification of the World Health Organization. The most frequent stage was II (50.0\%); most of the patients received chemotherapy, radiotherapy, and surgical treatment; the most frequent adjuvant pharmacological treatment during the intervention was hormonal therapy. $26.7 \%$ of the patients had controlled arterial hypertension, and one of them had controlled hypothyroidism. On average, patients began their participation in the study 29 months after diagnosis and 20.7 months after surgical treatment.

Table 3. Demographic data of the study population $(n=30)$.

\begin{tabular}{lc}
\hline Age $($ years $)$ & $52.0(41.0-66.0)$ \\
Height $(\mathrm{m})$ & $1.55(1.49-1.73)$ \\
Weight $(\mathrm{kg})$ & $70.2(49.2-87.7)$ \\
Stage $(\%)$ & 3.9 \\
0 & 19.2 \\
I & 50.0 \\
III & 23.0 \\
IV & 3.9 \\
Oncological Treatment $(\%)$ & \\
Chemotherapy & \\
Radiotherapy & 89.7 \\
Surgery & 53.6 \\
Axillary lymph node dissection & 63.3 \\
Mastectomy & 70.0 \\
Adjuvant pharmacological treatment (\%) & \\
None & 23.3 \\
Hormone therapy & 69.9 \\
Monoclonal antibodies & 6.7 \\
\hline
\end{tabular}




\begin{tabular}{lc}
\hline Co-morbidities (\%) & 26.7 \\
Hypertension & 3.3 \\
Hypothyroidism & \\
& \\
Level of education (\%) & 13.3 \\
Basic & 46.7 \\
High school & 33.3 \\
Undergraduate studies & 6.7 \\
Postgraduate studies & \\
\hline
\end{tabular}

Note. Data are presented as medians (minimum-maximum) and percentage.

Table 4. Study variables at baseline and at the end of the intervention.

\begin{tabular}{|c|c|c|c|}
\hline Variables & $\begin{array}{c}\text { Baseline }(n=30) \\
\text { Week } 0\end{array}$ & $\begin{array}{c}\text { Final }(n=24) \\
\text { Week } 25\end{array}$ & $\Delta$ \\
\hline \multicolumn{4}{|l|}{ Cardiometabolic Risk } \\
\hline \multicolumn{4}{|l|}{ Anthropometry } \\
\hline BMI $\left(\mathrm{kg} / \mathrm{m}^{2}\right)$ & $28.9(19.6-35.8)$ & $28.0(19.4-34.0)^{*}$ & $-1.1[-1.5,-0.6]$ \\
\hline Waist (cm) & $93.9(77.5-120.3)$ & $93.3(71.5-115.1)^{*}$ & $-3.7[-2.3,-5.2]$ \\
\hline Fat Mass (\%) & $37.4(30.3-48.7)$ & $34.6(29.2-47.6)^{*}$ & $-3.0[-2.0,-3.9]$ \\
\hline Muscle mass (\%) & $28.1(17.8-33.2)$ & $30.8(18.3-35.9)^{*}$ & $2.9[3.9,1.9]$ \\
\hline \multicolumn{4}{|l|}{ Serum biochemistry tests } \\
\hline $\mathrm{HDL}(\mathrm{mg} / \mathrm{dL})$ & $45.5(25.0-104.9)$ & $47.0(32.0-77.0)$ & $2.4[-2.0,7.0]$ \\
\hline Triglycerides (mg/dL) & $146.0(61.0-530.0)$ & $154.0(63.0-222.0)$ & $-34.2[-72.0,3.5]$ \\
\hline Total Cholesterol (mg/dL) & $188.5(114.0-288.0)$ & $185.5(134.0-256.0)$ & $-7.9[-19.2,3.3]$ \\
\hline LDL (mg/dL) & $123.0(44.0-178.3)$ & $121.3(64.0-157.5)$ & $-2.5[-12.8,7.7]$ \\
\hline Glucose (mg/dL) & $95.5(67.0-111.0)$ & $91.5(67.0-115.0)$ & $-1.8[-6.0,2.4]$ \\
\hline Insulin $(\mu \mathrm{U} / \mathrm{ml})$ & $7.6(1.6-26.6)$ & $6.8(1.9-19.6)$ & $-1.7[-4.1,0.6]$ \\
\hline HOMA-IR & $1.8(.3-7.2)$ & $1.4(.4-5.2)$ & $-0.3[-1.0,0.2]$ \\
\hline \multicolumn{4}{|l|}{ Blood pressure } \\
\hline Systolic (mmHg) & $110.00(90.0-130.0)$ & $100.0(90.0-130.0)$ & $-3.5[-8.1,1.0]$ \\
\hline Diastolic (mmHg) & $69.0(60.0-80.0)$ & $60.0(60.0-80.0)$ & $-0.8[-4.4,2.7]$ \\
\hline \multicolumn{4}{|l|}{ Cardiorespiratory fitness } \\
\hline METs & $8.4(6.3-11.1)$ & $11.1(8.4-12.9)^{*}$ & $2.9[2.4,3.3]$ \\
\hline $\mathrm{VO}_{2 \max }\left(\mathrm{mL}^{*} \mathrm{~kg}^{-1 *} \mathrm{~min}^{-1}\right)$ & $29.4(22.0-38.8)$ & $38.8(29.4-45.1)^{*}$ & $10.1[8.5,11.7]$ \\
\hline \multicolumn{4}{|l|}{ Quality of life } \\
\hline SF-36 & $77.8(38.0-96.2)$ & $87.0(45.7-98.1)^{*}$ & $9.0[5.0,13.0]$ \\
\hline Physical health & 76.8 (36.8-93.7) & $85.9(53.1-96.2)^{*}$ & $12.0[7.6,16.5]$ \\
\hline Mental health & $76.4(36.0-100.0)$ & $88.1(36.1-100.0)$ & $5.9[-0.8,12.7]$ \\
\hline FACT-B & $114.0(81.1-137.0)$ & $121.5(100.3-145.0)^{*}$ & $11.1[6.9,15.2]$ \\
\hline TOI & $71.4(52.0-89.0)$ & $77.0(60.0-93.0)^{*}$ & $8.9[6.0,11.7]$ \\
\hline \multicolumn{4}{|c|}{$\begin{array}{l}\text { Note. Data are presented as medians (minimum-maximum). } \Delta=\text { final value - baseline value, presented as mean [CI 95\%]. BMI: Body mas } \\
\text { index; HDL: High density lipoproteins-cholesterol; LDL: Low density lipoproteins-cholesterol; METs: Metabolic equivalents; } V_{2 m a x} \text { : Maximun } \\
\text { oxygen uptake. TOI (Trial Outcome Index) = physical well-being + functional well-being + sub-scale of breast cancer. *Significantly differen } \\
\text { relative to baseline (Wilcoxon signed test, } p<.05 \text { ). }\end{array}$} \\
\hline
\end{tabular}


At the end of the intervention, there was an improvement in the study variables, which was significant for cardiorespiratory fitness and quality of life (Table 4). Likewise, there was a significant decrease in BMI, waist, percentage of fat mass, and an increase in muscle mass. The biochemical variables improved; however, the changes were not statistically significant.

Changes on the cardiometabolic risk factors observed in the patients at baseline and at the end of the intervention are shown in Table 5.

Table 5. Percentage of patients with cardiometabolic risk factors at baseline and at the end of the intervention.

\begin{tabular}{|c|c|c|}
\hline Variables & $\begin{array}{c}\% \text { Baseline }(n=30) \\
\text { Week } 0\end{array}$ & $\begin{array}{c}\% \text { Final }(n=24) \\
\text { Week } 25\end{array}$ \\
\hline \multicolumn{3}{|l|}{ Anthropometry } \\
\hline $\mathrm{BMI}>24.9\left(\mathrm{~kg} / \mathrm{m}^{2}\right)$ & 76.6 & 75.0 \\
\hline Waist $>88(\mathrm{~cm})$ & 80.0 & 62.5 \\
\hline \multicolumn{3}{|l|}{ Serum biochemistry tests } \\
\hline $\mathrm{HDL}<50(\mathrm{mg} / \mathrm{dL})$ & 70.0 & 58.3 \\
\hline Triglycerides > $150(\mathrm{mg} / \mathrm{dL})$ & 46.6 & 50.0 \\
\hline Cholesterol > 200 (mg/dL) & 40.0 & 20.8 \\
\hline $\mathrm{LDL}>100(\mathrm{mg} / \mathrm{dL})$ & 66.6 & 66.6 \\
\hline Glucose > 100 (mg/dL) & 30.0 & 16.6 \\
\hline HOMA-IR > 2.4 & 26.6 & 20.8 \\
\hline \multicolumn{3}{|l|}{ Cardiorespiratory fitness } \\
\hline METs $<7.94$ & 30.0 & 0.0 \\
\hline $\mathrm{VO}_{2 \max }<27.79 \mathrm{~mL}^{*} \mathrm{~kg}^{-1 *} \mathrm{~min}^{-1}$ & 30.0 & 0.0 \\
\hline
\end{tabular}

The nutritional recommendations for the patients allowed the decrement of $303 \mathrm{Kcal} /$ day on average on their usual diet and the significant increment of $2.2 \%$ in the consumption of protein.

\section{DISCUSSION}

The objective of the study was to evaluate the effect of a combined, individualized and progressive physical exercise program on cardiometabolic risk factors and the quality of life of women survivors of breast cancer.

Among cardiometabolic risk factors, cardiorespiratory fitness is a strong predictor of mortality from any cause and per cardiovascular event in general population (Kodama et al., 2009). Regarding women, it has been estimated that a cardiorespiratory capacity superior to $8 \mathrm{METs}\left(28 \mathrm{~mL} / \mathrm{kg}^{*} \mathrm{~min}\right)$ represents a substantially lower risk of death from any cause compared to those with a lower cardiorespiratory capacity (Gulati et al., 2003). It has been reported that in the case of women surviving breast cancer, the cardiorespiratory capacity after the treatments received is approximately $25.0 \%$ lower than that observed in sedentary women of the same age but without a history of cancer (Beaudry et al., 2018; Jones et al., 2012). This is the reason why it is considered an important prognostic factor for recurrence of the disease and survival; therefore, an 
important objective for these patients is to maintain an adequate level of cardiorespiratory fitness throughout the continuum of breast cancer survival (Jones et al., 2012).

At the beginning of this study, 9 patients $(30.0 \%)$ had values below 8 METs but at the end of the intervention, all patients showed improved cardiorespiratory fitness with an overall increment of 2.9 METs, thus reducing the risk of death due to any cause to $17.0 \%$ for each MET increased (Gulati et al., 2003). On the other hand, the cardiorespiratory capacity expressed as oxygen consumption had an average global increment of 10.1 $\mathrm{mL}^{*} \mathrm{~kg}^{-1 *} \mathrm{~min}^{-1}(31.9 \%)$, this change was larger than the one reported in Beaudry et al. (2015) and Jones et al. (2011) meta-analysis of 3.13 and $2.9 \mathrm{~mL}^{*} \mathrm{~kg}^{-1 *} \mathrm{~min}^{-1}$ respectively, but similar to the study by Scott et al. (2013) who reports a $32.0 \%$ increment after 24 weeks.

It has been suggested that the decrease in $\mathrm{VO}_{2}$ in the survivor of breast cancer could be a consequence of the deleterious effects of anti-cancer therapy that impair the reserve capacity of organs and systems that regulate the release, transport and supply of $\mathrm{O}_{2}$ (Jones et al., 2012) and it has been proven that interventions with physical exercise programs favour changes in cardiac, peripheral vascular, and musculoskeletal functions which are reflected in the increase in $\mathrm{VO}_{2}$ (Haykowsky et al., 2016; Lahart, Metsios, Nevill, Carmichael, 2018). This improvement in cardiorespiratory fitness reduces the likelihood of cardiovascular disease, which is the main cause of mortality in women survivors of breast cancer (Gernaat et al., 2017; Riihimäki, Thomsen, Brandt, Sundquist, Hemminki, 2012).

The magnitude of the changes observed in cardiorespiratory fitness is related to the management of the training variables (modality, volume, intensity, frequency and progression). The best results are obtained when the program design combines aerobic and strength training, which increases physical demand periodically once a steady state is reached (progressive overload) (Battaglini et al., 2014). In this study, an increase in the volume and intensity of aerobic exercise was applied beginning at week 12 (session 40); this design improved cardiorespiratory fitness 3 times more if compared to the results obtained with exercise programs of similar volume and intensity, but that did not take into account the progression variable in the design (Beaudry et al., 2015; Jones et al., 2011).

Another cardiometabolic risk factor present in these patients is the weight gain that manifests as an increase in BMI which leads to an increase in body fat mass, mainly in the abdominal region, and a decrease in muscle mass. This condition leads to a phenotype of body composition known as sarcopenic obesity (Irwin et al., 2005). It has been considered that the weight gain observed in patients after oncological treatments may be due to a decrease in total energy expenditure, a lower resting metabolic rate, less physical activity, and important changes in diet (Gadéa, Thivat, Planchat, Morio, Durando, 2012). On the one hand, Nichols et al. (2009) reported that for women who gained weight after breast cancer diagnosis, the risk of specific death from breast cancer increased $13.0 \%$, from any cause $12.0 \%$, and from cardiovascular disease $19.0 \%$ for every $5 \mathrm{~kg}$ of increase in weight. On the other hand, Chan et al. (2014) estimated that 12 months after the diagnosis, for each increase of $5 \mathrm{~kg} / \mathrm{m}^{2}$ in BMI, the patients' total risk of death increases $11.0 \%$ whereas risk of mortality from breast cancer increases in $14.0 \%$.

The anthropometric results of the present study show that the exercise program led to the average reduction of $1.1 \mathrm{~kg} / \mathrm{m}^{2}$ in the BMl equivalent to $2.6 \mathrm{~kg}$ for a woman with average height of $1.55 \mathrm{~m}$, improved body composition by reducing the percentage of fat mass in 3.0\%, and increased the percentage of muscle mass in $2.9 \%$. The significant decrease obtained in the waist circumference indicates a decrease in abdominal fat. The changes observed are considered favourable; however, the causal mechanisms from which the weight loss or the modification in the body composition after the diagnosis improves survival have not been 
elucidated. What is known so far is that the accumulation of fatty tissue, mainly in the abdominal region, and high insulin levels promote insulin resistance, which is considered a metabolic status predictor of the development of chronic diseases such as metabolic syndrome, diabetes mellitus, and cardiovascular disease, conditions that, as for the general population, increase the risk of death due to cardiovascular disease and in the case of the population affected by cancer, deteriorate the quality of survival (Gadéa et al., 2012).

At the beginning of the present study, $77.0 \%$ of the patients were overweight or obese and $80.0 \%$ had a high waist circumference; with these anthropometric characteristics, $27.0 \%$ of the patients had insulin resistance, $67.0 \%$ elevation of LDL, $40.0-47.0 \%$ elevation of cholesterol and triglycerides, and $70.0 \%$ decreased $\mathrm{HDL}$. At the end of the intervention, $17.0 \%$ of the patients managed to reduce the waist circumference to healthy values, $19.0 \%$ decreased their cholesterol levels, and 12\% improved the HDL levels; the rest of the biomarkers did not present substantial changes. However, it is important to point out that during the intervention the patients only received nutritional recommendations, that is to say, there was not a direct intervention on the composition or caloric intake. This is relevant since it has been observed in overweight or obese patients with any of the components of the metabolic syndrome and without a history of cancer, that the combination of diet and exercise has a greater impact on the modification of these biomarkers compared to the result of separate interventions (Shaw, Gennat, O'Rourke, Del Mar, 2006), therefore, monitoring closely the nutritional habits of the physically active survivor of breast cancer could promote better outcomes in her quality of survival.

The intervention with supervised exercise, besides improving the cardiorespiratory capacity and body composition, was accompanied with a better perception of the quality of life. The average general change observed with the FACT-B questionnaire of 11.1 points is above the range considered as the minimum difference of clinical importance (MDCl) of 7-8 points, while the TOI is 2.9 points higher than the $\mathrm{MDCl}$ range of 5.0-6.0 points (Webster, Cella, Yost, 2003). Additionally, according to the SF36 questionnaire, the improvements observed in the physical and mental health scales (12.0 and 5.9 points) are also above the range observed as $\mathrm{MDCl}$ of 3.0 points for both scales (Fong et al., 2012). These results show that the exercise program significantly favoured the perception of a better state of health in the physical/functional domain.

Within the limitations of the present study, the absence of a control group does not allow attributing the observed changes to the specific intervention with the exercise program. However, the significant changes obtained in cardiorespiratory fitness and body composition reflect the pattern observed in therapeutic interventions with exposure to exercise in this population. Another limitation of this study lies in the lack of a specific diet plan for weight loss; the change in the energy balance impacts on the path associated with obesity and the prognosis of recurrence of the disease or the development of other comorbidities. This path also involves the practice of physical exercise, so the combination of both interventions would further favour the expected changes.

Among the strengths of this study, it can first be mentioned that within the proposed exercise program, the progression was taken into account; this variable allows reaching important physiological adaptations more quickly. Another positive element was the permanent supervision by trained personnel during the execution of the exercises; this favoured the absence of adverse events and the adherence to the intervention. Additionally, it allowed evaluating the patients' acceptance and tolerance to the effort. 


\section{CONCLUSIONS}

In conclusion, it can be said that the program of combined exercise (strength and aerobic), supervised and progressive, of 24 week duration, was effective to increase the cardiorespiratory capacity and positively modify the body composition, which are considered as important components of functional capacity (fitness) in the breast cancer survivor. These changes contributed to a better perception of quality of life on the part of the patients, mainly in the domain of physical/functional health.

\section{ACKNOWLEDGEMENTS}

The authors wish to acknowledge the technical support and clinical assistance of Nurse Nancy GutiérrezFernández, Nutritionists Fernando Valencia-León and Bricia Lara-Cortázar, and Social Worker Irma Velázquez-Barrera from NCRCSM (NIRLGII); also, the clinical advisory of MD Claudia Arce-Salinas and MD Leticia Mendoza from The National Cancer Institute, Mexico City, Mexico.

They also wish to acknowledge the financial support received from the Chief Executive Officer of Health Education of the Ministry of Health, Mexico, through the Quality Program in Health Care in the year 2015 (Official Document DGCES-DG-01649-2015).

Authors confirm that the study was undertaken in compliance with the Helsinki Declaration and The Regulation of the General Health Law on Health Research, Mexico.

\section{CONFLICTS OF INTEREST}

The authors certify that there is no conflict of interests with any financial organization regarding the material discussed in the manuscript.

\section{REFERENCES}

Allemani, C., Weir, H.K., Carreira, H., Harewood, R., Spika, D., Wang, X.S.,...Coleman, M.P. (2015). Global surveillance of cancer survival 1995-2009: analysis of individual data for 25676887 patients from 279 population-based registries in 67 countries (CONCORD-2). Lancet, 385(9972), 977-1010. https://doi.org/10.1016/s0140-6736(14)62038-9

American College of Sports Medicine. (2017). ACSM's guidelines for exercise testing and prescription. Philadelphia: Lippincott Williams \& Wilkins.

Battaglini, C.L., Mills, R.C., Phillips, B.L., Lee, J.T., Story, C.E., Nascimento, M.G. \& Hackney, A.C. (2014). Twenty-five years of research on the effects of exercise training in breast cancer survivors: a systematic review of the literature. World Journal of Clinical Oncology, 5(2), 177-190. https://doi.org/10.5306/wico.v5.i2.177

Beaudry, R., Kruger, C., Liang, Y.Y., Parliament, M., Haykowsky, M. \& McNeely, M.L. (2015). Effect of supervised exercise on aerobic capacity in cancer survivors: adherence and workload predict variance in effect. World Journal of Meta-Analysis, 3(1), 43-53. https://doi.org/10.13105/wima.v3.11.43

Beaudry, R.I., Liang, Y., Boyton, S.T., Tucker, W.J., Brothers, M., Daniel K.M.,... Haykowsky, M. (2018). Meta-analysis of exercise training on vascular endothelial function in cancer survivors. Integrative Cancer Therapies, 17(2), 192-199. https://doi.org/10.1177/1534735418756193 
Bodai, B.I. \& Tuso, P. (2015). Breast cancer survivorship: a comprehensive review of long-term medical issues and lifestyle recommendations. The Permanent Journal, 19(2), 48-79. https://doi.org/10.7812/tpp/14-241

Bray, F., Ferlay, J., Soerjomataram, I., Siegel, R.L., Torre, L.A. \& Jemal, A. (2018). Global cancer statistics 2018: GLOBOCAN estimates of incidence and mortality worldwide for 36 cancers in 185 countries. CA A Cancer Journal for Clinicians, 68(6), 394-424. https://doi.org/10.3322/caac.21492

Chan, D.S., Vieira, A.R., Aune, D., Bandera, E.V., Greenwood, D.C., McTiernan, A.,...Norat, T. (2014). Body mass index and survival in women with breast cancer-systematic literature review and metaanalysis of 82 follow-up studies. Annals of Oncology, 25, 1901-1914. https://doi.org/10.1093/annonc/mdu042

Fernández-Suárez HG, Blum-Grynberg B, Aguilar-Villalobos EJ, et al. Validación de un instrumento para medir calidad de vida en pacientes con cáncer de mama. Rev Med Inst Mex Seguro Soc. 2010;48(2):133-138.

Fong, D.Y., Ho, J.W., Hui, B.P., Lee, A.M., Macfarlane, D.J., Leung, S.S.,...Cheng, K.K. (2012). Physical activity for cancer survivors: meta-analysis of randomized controlled trials. British Medical Journal, 344, e70. https://doi.org/10.1136/bmj.e70

Gadéa, E., Thivat, E., Planchat, E., Morio, B. \& Durando, X. (2012). Importance of metabolic changes induced by chemotherapy on prognosis of early-stage breast cancer patients: a review of potential mechanisms. Obesity Reviews, 13(4), 368-380. https://doi.org/10.1111/j.1467-789x.2011.00957.x

Garcia, D.O. \& Thomson, C.A. (2014). Physical activity and cancer survivorship. Nutrition in Clinical Practice, 29(6), 768-779. https://doi.org/10.1177/0884533614551969

Gernaat, S.A.M., Ho, P.J., Rijnberg, N., Emaus, M.J., Baak, L.M, Hartman M.,...Verkooijen, H.M. (2017). Risk of death from cardiovascular disease following breast cancer: a systematic review. Breast Cancer Research and Treatment, 164(3), 537-555. https://doi.org/10.1007/s10549-017-4282-9

Gulati, M., Pandey, D.K., Arnsdorf, M., Lauderdale, D., Thisted, R., Wicklund, R.H.,...Black, H.R. (2003). Exercise capacity and the risk of death in women. The St James women take heart project. Circulation, 108(13), 1554-1559. https://doi.org/10.1161/01.cir.0000091080.57509.e9

Haykowsky, M.J., Beaudry, R., Brothers, R.M., Nelson, M.D., Sarma, S. \& La Gerche, A. (2016). Pathophysiology of exercise intolerance in breast cancer survivors with preserved left ventricular

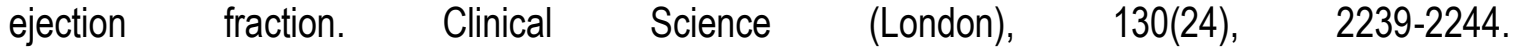
https://doi.org/10.1042/cs20160479

Haykowsky, M.J., Scott, J.M., Hudson, K. \& Denduluri, N. (2017). Lifestyle interventions to improve cardiorespiratory fitness and reduce breast cancer recurrence. American Society of Clinical Oncology Educational Book, 37, 57-64. https://doi.org/10.14694/edbk_175349

Heyward, V.H. \& Wagner, D.R. (2004). Body composition and metabolic diseases. In: Heyward, V.H. \& Wagner, D.R. (Eds), Applied body composition assessment (pp.185-193). Champaign, IL: Human Kinetics.

Heyward, V.H. (2008). Evaluación de la aptitud física y prescripción del ejercicio. Madrid, España: Ed. Médica Panamericana.

Irwin, M.L., McTiernan, A., Baumgartner, R.N., Baumgartner, K.B., Bernstein, L., Gilliland, F.D. \& BallardBarbash, R. (2005). Changes in body fat and weight after a breast cancer diagnosis: influence of demographic, prognostic, and lifestyle factors. Journal of Clinical Oncology, 23(4), 774-782. https://doi.org/10.1200/jco.2005.04.036

Jones, L., Courneya, K., Mackey, J., Muss, H., Pituskin, E., Scott, J.,...Haykowsky, M. (2012). Cardiopulmonary function and age-related decline across the breast cancer survivorship continuum. Journal of Clinical Oncology, 30(20), 2530-2537. https://doi.org/10.1200/jc0.2011.39.9014 
Jones, L.W., Liang, Y., Pituskin, E.N., Battaglini, C.L., Scott, J.M., Hornsby, W.E. \& Haykowsky, M. (2011). Effect of exercise training on peak oxygen consumption in patients with cancer: a metaanalysis. The Oncologist, 16(1), 112-120. https://doi.org/10.1634/theoncologist.2010-0197

Kodama, S., Saito, K., Tanaka, S., Maki, M., Yachi, Y., Asumi, M.,...Sone, H. (2009). Cardiorespiratory fitness as a quantitative predictor of all-cause mortality and cardiovascular events in healthy men and women: a meta-analysis. Journal of the American Medical Association, 301(19), 2024-2035. https://doi.org/10.1001/jama.2009.681

Kraemer, W.J., Adams, K., Cafarelli, E., Dudley, G.A., Dooly, C., Feigenbaum, M.S.,...Triplett-McBride, T. (2002). American College of Sports Medicine position stand. Progression models in resistance training for healthy adults. Medicine and Science in Sports and Exercise, 34(2), 364-380. https://doi.org/10.1097/00005768-200202000-00027

Lahart, I.M., Metsios, G.S., Nevill, A.M. \& Carmichael, A.R. (2018). Physical activity for women with breast cancer after adjuvant therapy. Cochrane Database of Systematic Reviews, 1:CD011292. https://doi.org/10.1002/14651858.cd011292.pub2

Lin, X., Zhang, X., Guo, J., Roberts, C.K., McKenzie, S., Wu, W.C.,...Song, Y. (2015). Effects of exercise training on cardiorespiratory fitness and biomarkers of cardiometabolic health: a systematic review and meta-analysis of randomized controlled trials. Journal of the American Heart Association, 4(7), e002014. https://doi.org/10.1161/jaha.115.002014

Maffuz-Aziz, A., Labastida-Almendaro, S., Sherwell-Cabello, S., Ruvalcaba-Limón, E., DomínguezReyes, C.A., Tenorio-Torres, J.A. \& Rodríguez-Cuevas, S. (2016). Supervivencia de pacientes con cáncer de mama. Análisis por factores pronóstico, clínicos y patológicos [In Spanish]. Ginecología y Obstetricia de México, 84(8), 498-506.

Información estadística cáncer de mama. (2016, December 2). Retrieved from https://www.gob.mx/salud\%7Ccnegsr/acciones-y-programas/informacion-estadistica-cancer-demama

Mishra, S.I., Scherer, R.W., Geigle, P.M., Berlanstein, D.R., Topaloglu, O., Gotay, C.C. \& Snyder, C. (2012). Exercise interventions on health-related quality of life for cancer survivors. Cochrane $\begin{array}{llll}\text { Database of Systematic } & \text { Reviews, } & \text { 15(8), }\end{array}$ https://doi.org/10.1002/14651858.cd007566.pub2

Nichols, H.B., Trentham-Dietz, A., Egan, K.M., Titus-Ernstoff, L., Holmes, M.D., Bersch, A.J.,...Newcomb, P.A. (2009). Body mass index before and after breast cancer diagnosis: associations with all-cause, breast cancer, and cardiovascular disease mortality. Cancer Epidemiology, Biomarkers \& Prevention, 18(5), 1403-1409. https://doi.org/10.1158/1055-9965.epi08-1094

Riihimäki, M., Thomsen, H., Brandt, A., Sundquist, J. \& Hemminki, K. (2012). Death causes in breast cancer patients. Annals of Oncology, 23(3), 604-610. https://doi.org/10.1093/annonc/mdr160

Scott, E., Daley, A.J., Doll, H., Woodroofe, N., Coleman, R.E., Mutrie, N.,...Saxton, J.M. (2013). Effects of an exercise and hypocaloric eating program on biomarkers associated with long-term prognosis after early-stage breast cancer: a randomized controlled trial. Cancer Causes and Control, 24(1), 181-191. https://doi.org/10.1007/s10552-012-0104-x

Shaw, K.A., Gennat, H.C., O'Rourke, P. \& Del Mar, C. (2006). Exercise for overweight or obesity. $\begin{array}{llll}\text { Cochrane Database of Systematic Reviews, 4, CD003817. } & \text {. }\end{array}$ https://doi.org/10.1002/14651858.CD003817.pub3

Webster, K., Cella, D. \& Yost, K. (2003). The functional assessment of chronic illness therapy (FACIT) measurement system: properties, applications, and interpretation. Health and Quality of Life Outcomes, 1, 79. https://doi.org/10.1186/1477-7525-1-79 
Zeng, Y., Huang, M., Cheng, A.S., Zhou, Y. \& So, W.K. (2014). Meta-analysis of the effects of exercise intervention on quality of life in breast cancer survivors. Breast Cancer, 21(3), 262-274. https://doi.org/10.1007/s12282-014-0521-7

Zúniga, M.A., Carrillo-Jiménez, G.T., Fos, P.J., Gandek, B. \& Medina-Moreno, M.R. (1999). Evaluación del estado de salud con la encuesta SF-36: resultados preliminares en México [In Spanish]. Salud Pública de México, 41(2), 110-118. https://doi.org/10.1590/s0036-36341999000200005

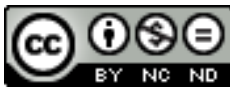

This work is licensed under a Attribution-NonCommercial-NoDerivatives 4.0 International (CC BY-NC-ND 4.0). 